butadiene: the cyclobutadiene-metal complexes; cyclobutadiene divalent ions; cyclobutadienequinone; methylene analogues of cyclobutadienequinone; benzocyclobutadiene; benzocyclobutadienequinone; methylene analogues of 1,2-benzocyclobutadienequinone; higher aromatic analogues of benzocyclobutadiene; biphenylene; benzobiphenylenes; and theoretical aspects of the cyclobutadiene problem. The monograph includes all relevant material published up to January 1, 1964, and there is an appendix containing abstracts of papers published in 1964 and 1965. In addition to published work much information has also been extracted from unpublished theses. The text is excellently written and is profusely illustrated with formulae, diagrams and tables.

The authors have admirably succeeded in their task and the book will be of great interest and value to workers on carbocyclic and on aromatic polycyclic compounds. It will be an essential work of reference for specialists in the field of four membered unsaturated rings and their benzo derivatives.

J. F. W. MсOмre

\section{CHEMISTRY OF ALKALOIDS}

\section{An Introduction to the Alkaloids}

By G. A. Swan. Pp. viii +326. (Oxford and Edinburgh: Blackwell Scientific Publications, 1967.) 63s. net.

THE problems facing an author who wishes to write an introduction to the alkaloids "suitable for advanced undergraduate and postgraduate students or for others wishing to begin a study of the subject" are daunting indeed. To make a reasonably comprehensive selection from the many classes of alkaloid, to include sufficient detail and thus avoid a sense of remoteness but at the same time to give a satisfactory general picture - these are just a few of the difficulties to be overcome. The present author has tackled these and other problems in a straightforward way and has produced a book which is instructive, up to date, comprehensive and extremely readable. Apart from an introductory chapter and a final chapter on biogenesis, the main body of the book is devoted to a description of the major classes of alkaloid, illustrated with carefully selected examples. The historical background is often described and accounts of classical degradative and synthetic work are complemented by numerous illustrations of the application of modern physical techniques such as ultraviolet, infrared, nuclear magnetic resonance and mass spectroscopy to problems of structure elucidation.

Aspects of the pharmacology of the alkaloids are also included and give added interest to the purely chemical sections.

The final chapter on biogenesis is up to date and very clearly written. The author has shown (for example, in the section on indole alkaloid biogenesis) how biogenetic studies can help to clarify and rationalize the relationships between alkaloids of apparently diverse structural types.

In a book of this nature, it is inevitable that some errors should have crept in-these, however, are very few in number and are usually of minor importance (for example, the formula for chaksine, page 275 , which lacks a methyl group). Nowadays, however, when so many publications of this type show obvious signs of having been written in great haste and with little thought, it is a real pleasure to come across one in which the author has combined experience, careful planning, accuracy and style, to produce a book which fully accomplishes the intentions quoted at the beginning of this review.

A book of this kind has been long needed and this volume can be thoroughly recommended (especially in view of the very reasonable price) to everyone interested in alkaloid chemistry, specialists and non-specialists alike.

\section{WORLD KEY TO ANGIOSPERMS}

Key to the Families of Flowering Plants of the World By J. Hutchinson. Revised and enlarged for use as a supplement to The Genera of Flowering Plants. Pp. vii + 117. (Oxford: Clarendon Press; London: Oxford University Press, 1967.) 30s. net; paperback edition $18 s$. However controversial Dr John Hutchinson's well known system of classification of flowering plants might be, the key to families included in the two editions of his Families of Flowering Plants has proved to be of outstanding value to botanists throughout the world. This latest book is simply a revised and rearranged version of the family key included in the 1959 second edition. The author intends it to serve as a complement to the most ambitious yet of his publications, The Genera of Flowering Plants, of which two volumes have so far been published in 1964 and 1967, respectively. There is no doubt that it will be widely used in the field and herbarium as a working key quite independently from the Genera or any other works. As the author says in the preface, "by means of this key it should be possible to determine the family of most of the flowering plants to be met with on a day's march in any part of the world, from the north and south poles to the equator or from Greenland's icy mountains to India's coral strand".

The book consists almost entirely of the keys. A short glossary is appended and there are two pages of diagrams illustrating terms used in the keys. There are separate keys to the Dicotyledons and Monocotyledons. The Dicotyledons are divided into thirty-two artificial groups, a larger number than in the Families, because the main ones are subdivided into smaller units so as to ease the task of identification. Many of these smaller groups are made on the basis of the presence of opposite or alternate leaves. Although the keys are deliberately artificial, Hutchinson cannot refrain from adding that alternate leaves are usually a more primitive character and opposite leaves more advanced.

A disastrous error occurs on page 102 when about half the key to group 1 of the Monocotyledons (about twentytwo lines to judge by the key on page 528 of Vol. 2 of The Families of Flowering Plants) is omitted, so that ten families (Typhaceae, Sparganiaceae, Lemnaceae, and so on) cannot be run down.

Mechanically the keys are good and the contents usually clear. They are not, however, always dichotomous: three or four contrasting leads are common-quite unnecessarily so in most cases-and are often confusing. There are few misprints but seldom significant, except perhaps "Leaves compound of 1-foliolate, pellucid-punctate" on page 14. Another that will baffle foreign readers is "often "healthy' plants" in the key to Ericaceae. The punctuation is careless in many places and should be revised in any reprint that is issued.

The keys as a whole represent an intellectual achievement of a very high order. It is difficult to imagine any competing versions being offered in the future, when, in any case, alternative methods of preparation and presentation of keys using electronic data processing will be available. Even today, it would be valuable to have the information given in Hutchinson's key available as a set of punched cards.

The brief glossary is somewhat scrappy and the definitions are often over-simplified: for example, "monoecious, unisexual flowers on the same plant"; "embryo, rudimentary plant still enclosed in the seed"; "pollen, the powdery contents of an anther (the male element of the flower)". It is difficult to believe that any serious user of the key will need to consult such an elementary list. It could well be omitted in a further edition.

Hutchinson's Keys will be a deservedly popular work, and both he and his publishers are to be commended for making it available as a separate and relatively inexpensive book.
V. H. Hexwood 